\title{
Oral and facial presentations to general practice
}

\section{Dimitrios Nikolarakos}

ECONOMIC DRIVERS have changed the way in which patients seek attention for oral and facial conditions. ${ }^{1}$ General medical practitioners are increasingly being asked to assess, diagnose and treat these problems. This is likely to manifest even more so during the COVID-19-related restrictions, which have resulted in a significant shutdown of dental practices in a number of regions.

Some of the most common general practice presentations revolve around regionally related structures such as the ear, nose and throat, so it is assumed by patients that general practitioners (GPs) can also manage problems of the mouth, jaws and teeth. However, medical practitioners' actual knowledge and confidence to treat orofacial conditions varies considerably in Australasia. ${ }^{2}$

Unfortunately, university education in medicine and dentistry has diverged over recent years. In the past, students in both disciplines shared common basic science and health streams in the early years of their degrees. Changes in the principles of health education have resulted in far less crossover of these disciplines. This has led to the two health professions becoming more isolated from each other and less aware of the issues and conditions each treat.

Australian Journal of General Practice has a long history of filling this educational void for its readers through the publication of case studies and review articles related to conditions of the mouth, jaws and teeth. ${ }^{3-7}$ This issue of the journal takes the commitment one step further by providing short, scientifically based reviews of some of the most common presentations. The topics presented in this edition ${ }^{8-13}$ were chosen to encompass issues that have not received review in the journal recently but may be of particular interest to GPs.

During the COVID-19 restrictions on dental services, GPs are likely to manage more people with dental pain, infection or other oral and facial conditions. GPs may also rely on oral and maxillofacial surgeons to advise or assist with such patients. Oral and maxillofacial surgery is a speciality of both medicine and dentistry. As such, it is the logical bridge between the two health professions. Despite the expansion of oral and maxillofacial surgery in Australia over the past 20 years, it remains a relative niche surgical specialty. Access to services in public and private practice in some locations can be challenging, particularly for patients who are underprivileged and those in rural and remote regions. ${ }^{14}$ These compounding problems further amplify the need for GPs to be comfortable assessing and managing oral and facial conditions.

\section{Author}

Dimitrios Nikolarakos MBBS, BDSc, FRACDS (OMS) FRCSEng (OMFS), Maxillofacial, Head \& Neck and Reconstructive Surgeon, Clinical Director Maxillofacial Unit, Gold Coast University Hospital, Qld; President, Australian and New Zealand Association of Oral and Maxillofacial Surgeons (ANZAOMS), NSW

\section{References}

1. Cope AL, Butt KG, Chestnutt IG. Why might patients in the UK consult a general medical practitioner when experiencing dental problems? A literature review of patients' perspectives. Community Dent Health 2018;35(4):235-40. doi: 10.1922/CDH_4369Cope06.

2. Samaei $H$, Weiland TJ, Dilley $S$, Jelinek GA. Knowledge and confidence of a convenience sample of Australasian emergency doctors in managing dental emergencies: Results of a survey. Emerg Med Int 2015;2015:148384. doi: 10.1155/2015/148384.

3. Diab J, David D, Grave B. A paediatric jaw lump: Desmoid tumour. Aust J Gen Pract 2019;48(6):380-83. doi: 10.31128/AJGP-0918-4703.

4. Farah CS. A keratinised lump on the lateral surface of the tongue. Aust J Gen Pract 2020;49(4):206-07. doi: 10.31128/AJGP-1019-5103.
5. Beech N, Tan-Gore E, Bohreh K, Nikolarakos D. Management of dental trauma by general practitioners. Aust Fam Physician 2015;44(12):915-18.

6. Beech N, Goh R, Lynham A. Management of dental infections by medical practitioners. Aust Fam Physician 2014;43(5):289-91.

7. Lynham A, Tuckett J, Warnke P. Maxillofacial trauma. Aust Fam Physician 2012;41(4):172-80.

8. Sen Gupta T, Stuart J. Medicine and dentistry: Shall ever the twain meet? Aust J Gen Pract 2020;49(9):544-48.

9. Cosson J. Interpreting an orthopantomogram. Aust J Gen Pract 2020;49(9):550-55.

10. Sherring D. Surgical solutions to orofacial problems. Aust J Gen Pract 2020;49(9):556-61.

11. Wong $T$, Yap T, Weisenfeld D. Common benign and malignant oral mucosal disease. Aust J Gen Pract 2020;49(9):568-73.

12. Wong T, Yap T, Weisenfeld D. Common causes of 'swelling' in the oral cavity. Aust J Gen Pract 2020;49(9):575-80.

13. Bayetto K, Cheng A, Goss A. Dental abscess: A potential cause of mortality and morbidity. Aust J Gen Pract 2020;49(9):563-67.

14. Kruger E, Tennant M. Accessing government subsidized specialist oral and maxillofacial surgery services in Western Australia. Aust Dent J 2005;50(3):168-72. doi: 10.1111/j.1834-7819.2005. tb00356.x. 